\title{
Las Bambas: conflicto social 2015
}

Recibido: 15/11/2017

Aprobado: 01/12/2017

\author{
Honorio Pinto Herrera \\ Universidad Nacional Mayor de San Marcos \\ < hpintoh@unmsm.edu.pe > \\ Antonio Luyo Quiroz \\ Universidad Nacional Mayor de San Marcos \\ < aluyo@unmsm.edu.pe >
}

\begin{abstract}
RESUMEN
El estudio trata sobre el proyecto minero Las Bambas (Apurímac) y el conflicto social que se desató a fines de setiembre del 2015. La protesta social fue breve pero intensa; tanto que el gobierno tuvo que declarar el estado de emergencia y tomar una serie de medidas para evitar el escalamiento del conflicto porque en esos días «Lima fue la capital económica del mundo». El trabajo trata de demostrar que las protestas tuvieron motivaciones objetivas porque los cambios en el EIA que hizo la empresa china (MMG) fueron sustanciales, pues dańarán áreas de influencia directa e indirecta. La magnitud de la protesta puso en agenda temas tan vigentes como el ordenamiento territorial, la zonificación económica ecológica, la consulta previa, las audiencias públicas, la licencia social, el extractivismo, contaminación ambiental, etc. El conflicto en las Las Bambas, con algunas particularidades, es el retrato de otros que han ocurrido en la gran minería del Perú.
\end{abstract}

PALABRAS ClAVE: Minería, Apurimac, Las Bambas, Conflicto Social.

\section{Las Bambas: Social conflict 2015}

\section{ABSTRACT}

The study deals with the mining project Las Bambas (Apurímac) and the social conflict that broke out at the end of September 2015. The social protest was brief but intense; So much so that the government had to declare a state of emergency and take a series of measures to avoid escalating the conflict because in those days "Lima was the economic capital of the world.» The paper tries to demonstrate that the protests had objective motivations because the changes made by the Chinese company (MMG) were substantial, as they will damage areas of direct and indirect influence. The magnitude of the protest brought to the fore issues such as territorial planning, ecological economic zoning, prior consultation, public hearings, social license, extractivism, environmental pollution, etc. The conflict in the Las Bambas, with some peculiarities, is the portrait of others that have occurred in the great mining of Peru.

KEYWORDS: Mining, Apurimac, Las Bambas, Social Conflict 


\section{Introducción}

D esde los inicios de la década del 90 del siglo xx, la gran minería en el Perú ha tenido un crecimiento significativo. Es una explotación intensiva en capital, con enormes ganancias, remuneraciones bajas y muchas ventajas para la gran inversión nacional e internacional. Algunos nombres confirman la afirmación anterior: Yanacocha, Pierina, Antamina, Tintaya, Antapaccay, Cerro Verde, Toquepala, Cuajone, Quellaveco, Shougang, Las Bambas, etc.

Este crecimiento de la gran minería está acompañado de muchos e intensos conflictos, los mismos que son multidimensionales, no tienen que ver únicamente con el factor económico, sino que también hay que tener en cuenta factores sociales, ambientales y culturales ${ }^{1}$. Flores (2016), siguiendo a CooperAcción, afirma que hay dos tipos de conflictos: unos que se pueden calificar como de resistencia y rechazo a los proyectos mineros (Tambogrande, Cerro Quilish, Río Blanco, Santa Ana, Conga, Tía María, etc.); otros conflictos que son de coexistencia con la minería (Tintaya, Las Bambas, Antamina, minas de la sierra central, etc.).

Ambos tipos de conflictos han dejado costos significativos. Según la Defensoría del Pueblo entre el 2006 y Junio del 2016 fallecieron 266 personas y el número de heridos llegó a 4511. En todos estos conflictos acontecidos en la gran minería se destaca la oposición entre dos fuerzas: la primera está constituida por el gobierno nacional y la empresa minera; la segunda por las organizaciones sociales y sus dirigentes. Los enfrentamientos entre ellos han sido frecuentes $\mathrm{y}$ muchas veces violentos. Es la lucha entre quienes promueven la actividad minera y los que se oponen a ella por diversos motivos. $\mathrm{Al}$ respecto

de acuerdo con las mineras y el gobierno, no hay lugar para muchas preocupaciones. El argumento central es que "el país necesita inversiones» y que no debe haber temores porque se usan avanzadas tecnologías y abundan los controles. Según las propias empresas, los problemas ambientales y sociales ocasionados están siendo hoy manejados adecuadamente. A diferencia de los viejos enclaves, los nuevos piden «licencia social» para operar, desarrollan «programas de responsabilidad social» $\mathrm{y}$

$\overline{1 \quad \text { Ver Gouley (2005). }}$ apoyan el «desarrollo sustentable». Sus actividades siguen "códigos de conducta» establecidos desde las casas matrices de las transnacionales, practican la autorregulación adoptando «estándares de calidad» internacionales. Si hay conflicto es porque existen «agitadores» políticos interesados en ganar titulares y ocupar cargos, pero el pueblo está a favor de la mina, y la mina a favor del pueblo, porque sin ella no habría progreso y el país perdería valiosos recursos (Durand, 2009)

Acerca de la conflictidad social es necesario consignar algunos otros puntos de vista: 1) «Ya antes se intentó convencernos de que la conflictividad social era producto de un gran grupo de terroristas antimineros, de personajes cuya única motivación era la política, de poblaciones a las que un grupo minúsculo de líderes podían movilizar como si fuesen ganado de un gobierno blando" (Rivera 2015, setiembre, Poder (editorial). 2) «...en el gremio minero, salvo honrosas excepciones, lo que ha primado es la teoría de la conspiración que en su forma más elemental, expresa una visión maniquea de la realidad: los mineros son aquellos que buscan el bien y sus críticos y opositores son la representación del mal... Así en los últimos quince años hemos visto a un solo bueno, la empresa; y a diversos malos: Puka Llacta, el antaurismo etnocacerista, el Ollanta de polo rojo, las ONG «caviares» nacionales y extranjeras, el neosenderista Movadef, el eterno Patria Roja, los curas «rojos», los narcos antimineros, los violentos aymaras, los frentes de defensa de todo tipo, el presidente regional y el alcalde "ultra», el dirigente "corrupto», entre otros» (Torres, 2015). 3). Según De Echave (2013) esta tesis (del complot) tiene varios problemas, él remarca dos: a) Homogeniza los conflictos, todo es un complot contra el país, contra las inversiones, contra la minería; los actores son los partidos políticos radicales, sindicatos, operadores políticos; los conflictos no son iguales, por lo tanto, las fómulas tampoco tienen que ser exactamente las mismas. b) Todo es visto como ilegítimo, no hay ninguna capacidad de reconocer cuál es la agenda que está detrás de los conflictos, cuáles son las bases objetivas que los explican.

En Apurímac, los conflictos sociales seguirán la tendencia que muestra el gráfico siguiente. A medida que avance la explotación minera en Las Bambas, se incrementarán los conflictos socioambientales.

La empresa minera, el gobierno nacional y muchos medios de comunicación han puesto énfasis en lo que expresan Durand, Rivera, Torres y De Echave por eso 


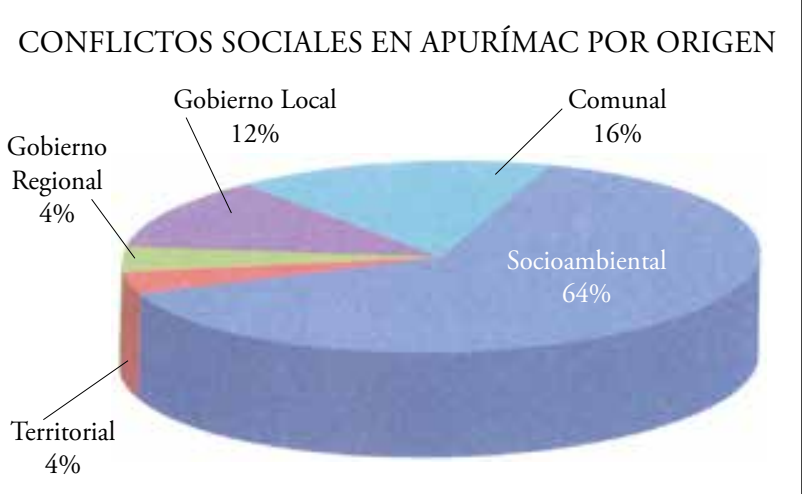

Fuente: Informe de la Defensoría de Pueblo. Abril 2014.

la conflictividad social no se supera en las Bambas. No se aprendió las lecciones de Cerro Quilish, Conga, Santa Ana, Tintaya y Tía María.

Este trabajo trata el conflicto minero ocurrido en las Bambas (Apurímac, Cotabambas) en setiembre del 2015. Cuando ocurre este hecho para muchas instituciones e individuos les resultó algo sorpresivo. Esto se explicaba porque la información mediática, entre otras, difundía la imagen de relaciones armoniosas en ese centro minero entre gobierno nacional, empresa y comunidades. Esta percepción no se ajustaba a la realidad y el recuento de conflictos que sigue lo comprueba: "Desde que entró Xstrata a la zona, los paros y las manifestaciones han ocurrido con regularidad; algunas protestas claves se produjeron en setiembre de 2006, julio de 2007, mayo de 2008, mayo de 2011, junio de 2012, agosto de 2013 y febrero de 2015 (Auccapure 2014: 19-20). Uno de los de mayor gravedad fue el paro del 15 y 16 de mayo de 2011, en el cual se produjeron importantes protestas en Challhuahuacho. En esa oportunidad, incluso un ingeniero de la empresa fue secuestrado para obligar a esta a negociar con la población e, igualmente, hubo una violenta represión por parte de la policía unos días después de este suceso. Del mismo modo, el paro de 72 horas realizado a partir del 6 de febrero de 2015 en Challhuahuacho, con la retención temporal de un grupo de empleados de una empresa subcontratista, llevó a la conformación de una mesa de desarrollo en este distrito, convocada por el gobierno nacional, organizaciones locales (promotoras del paro) y la alcaldía distrital» (Flores 2016).

La cita anterior prueba que los problemas en Las Bambas, llegaron con Xstrata en 2004 y, en este sentido, el conflicto derivado del paro indefinido iniciado a partir del 25 de setiembre es uno de tantos como se vuelve a comprobar con lo ocurrido el 14 de octubre de 2016, donde la protesta de cuatro comunidades (Allahua, Pumamarca, Choquecca Antuyo y Quehuira) terminó con la muerte de Quintino Cereceda Huisa lo que escaló el conflicto concitando la atención nacional e internacional. Además, el 8 de febrero del 2017 se inició un nuevo paro indefinido porque el gobierno y el consorcio chino MMG (conformado por MMG, accionista mayoritario que tiene calidad de operador con el 62.5\%; una subsidiaria propiedad de Gouxin International Investment con el $22.5 \%$ y CITIC Metal Co. Ltd. con el 15\%), han incumplido compromisos asumidos anteriormente.

El objetivo del trabajo es mostrar que el conflicto del 2015 en Cotabambas es la consecuencia de la acumulación de problemas no resueltos por la empresa minera y el gobierno nacional.

En el contenido de este trabajo se destaca: la ubicación del proyecto, los actores, los principales acontecimientos (antes, durante y después del conflicto), el análisis y discusión, etc. Para el desarrollo de esta última parte se ha seleccionado: Las Bambas ¿modelo de buenas relaciones?, el nuevo dueño y cambios en el estudio de impacto ambiental (EIA), diálogos sin resultados y mesas que mecen.

La realización del trabajo ha sido posible gracias a la información obtenida en: boletines electrónicos y otros estudios de CooperAcción, Observatorio de Conflictos Mineros, Defensoría del Pueblo, periódicos (El Comercio, La República, Correo, Perú 21, Expreso, Gestión, Hildebrandt en sus Trece), revistas (Caretas, Semana Económica, Minería, Velaverde, etc.), programas radiales y televisivos. Más información se obtuvo en las fuentes que figuran en las referencias bibliográficas. Es obvio el uso de la técnica documental y la triangulación.

\section{Ubicación del Proyecto ${ }^{2}$}

El proyecto minero Las Bambas (PMLB), se ubica en los distritos de Challhuahuacho y Progreso, de las provincias de Cotabambas y Grau respectivamente, en el departamento de Apurímac. Se encuentra entre los 3,800 y $4,650 \mathrm{msnm}$.

2 Información basada en los trabajos de CooperAcción (2015) y ProInversión (2005). 
El proyecto Las Bambas, comprendía inicialmente tres áreas: el área Las Bambas, el área del mineroducto y el área de Tintaya. Estas áreas se ubican en las regiones de Apurímac y Cusco.

- Elárea Las Bambas (Región Apurímac), constituida por: la mina, los botaderos, la planta concentradora con una capacidad de 140,000 toneladas diarias y los componentes auxiliares (laboratorios, áreas de almacenamiento, talleres, caminos internos, campamentos, oficinas, reservorios, bocatomas, entre otros).

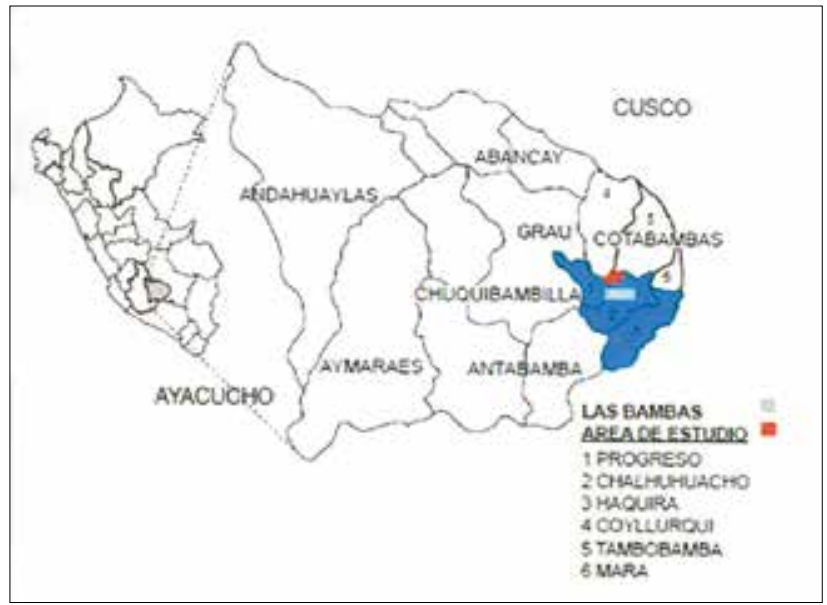

- El área del Mineroducto, comprendía $206 \mathrm{Km}$ de ducto, que partía de la planta concentradora, atravesaba la provincia de Cotabambas (Región Apurímac) y las provincias de Chumbivilcas y Espinar (región Cusco). El destino final, estaba en las plantas de molibdeno y filtros, ubicadas en la mina Tintaya (Espinar, Cusco). El mineroducto debía transportar concentrados de cobre $y$ molibdeno. Otros componentes de esta área eran las cuatro estaciones de bombeo ubicadas a lo largo del recorrido, piscinas de emergencia, además de una línea de energía eléctrica para las estaciones de bombeo.

- El área de Tintaya, (provincia de Espinar, Cusco). A esta área llegaba el mineroducto, para la realización del procesamiento de los concentrados de cobre y molibdeno. Sus componentes eran: la planta de Molibdeno, la planta de filtros y los almacenes. Según el EIA, esta área resultaba estratégica, debido a las sinergias que debían producirse entre la operación Tintaya y el Proyecto Las Bambas.
Desde la aprobación del primer Estudio de Impacto Ambiental (EIA) en el 2011, el proyecto ha tenido cinco modificaciones de sus componentes con respecto a su configuración inicial.

El PMLB fue adjudicado a la empresa suiza Xstrata en 2004. Después pasó a manos de Glencore-Xstrata en 2013 y finalmente al Consorcio MMG, liderado por la empresa china Minmetals Corporation, a partir de 2014.

\section{Actores}

La Defensoría del Pueblo (2015) señala los siguientes:

- Actores primarios: Federación Campesina de Challhuahuacho, Frente de Defensa de los Intereses del distrito de Challhuahuacho, alcalde Distrital de Challhuahuacho, Comunidades Campesinas del Área de Influencia Indirecta del Proyecto Minero Las Bambas (veintisiete comunidades), empresa Minera Xstrata Copper - Proyecto Las Bambas (actualmente adquirida por el consorcio MMG Ltd., filial externa de China Minmetals Corp.).

- Actores secundarios: Presidente Regional de Apurímac, Ministerio de Energía y Minas (MINEM), Ministerio de Educación (MINEDU), Ministerio de Vivienda, Construcción y Saneamiento (MVCS), Ministerio de Salud (MINSA), Ministerio del Ambiente (MINAM), Ministerio de Agricultura y Riego (MINAGRI), Ministerio de Desarrollo e Inclusión Social (MIDIS), Ministerio de Trabajo y Promoción del Empleo (MINTRA), Consejera Regional por Cotabambas, XVI Región Policial Apurímac (PNP), Empresa Bechtel (subcontratista de Xstrata Las Bambas para la construcción del campamento minero), Asociación de Hoteleros y Lavanderos de Challhuahuacho.

- Actores terciarios: Defensoría del Pueblo, Oficina Nacional de Diálogo y Sostenibilidad (ONDS), de la Presidencia de Consejo de Ministros.

Hay que destacar, además, los nombres de algunos dirigentes: Rodolfo Abarca, Presidente del Frente de Defensa de la Provincia de Cotabambas; Ronald Bello, Presidente del Frente de Defensa de Tambobamba; Wilber Venegas, presidente regional de Apurímac; Cosme Bolívar y José Portugal, Representantes de las 17 comunidades del área de influencia directa (AID) 
del PMLB; Alem Torres, asesor de los dirigentes; Jaime Osorio, Virginia Pinares; Carlos Vargas, vocero del Frente Social de Defensa de las Provincias de Cotabambas y Grau; etc.

\section{Causas}

Entre las más relevantes se pueden destacar:

- La negativa del gobierno a informar a las comunidades sobre las modificaciones en el EIA de Las Bambas. Solo tenían conocimiento parcial la mayoría de autoridades.

- El no cumplimiento de las 17 condiciones sociales contenidas en el anexo $\mathrm{K}$.

- Las cinco modificatorias al EIA amparadas en el D.S. No 054-2013-PCM. Este decreto supremo permite a las empresas modificar el EIA sin realizar nuevas audiencias o talleres, tan sólo presentando un Informe Técnico Sustentatorio (ITS) y un Plan de Participación Ciudadana (PPC).

- Debido a las modificaciones del EIA disminuyen las áreas de influencia directa e indirecta. En consecuencia quedan excluidas muchas comunidades y centros poblados de los posibles beneficios del proyecto minero.

- La presentación de actas de talleres supuestamente manipuladas y el desconocimiento de parte de MMG de los compromisos asumidos por Glencore, Xstrata. El cambio de dueño de las Bambas ha agudizado el conflicto.

- La violencia institucional del Estado expresada en la presencia de la PNP y de militares en la región. Hecho que se da en la etapa de construcción de la mina y que se ha agudizado ahora en la etapa de explotación.

Gouley (2005) destaca otras más: la contaminación o su amenaza, la distribución de los beneficios de la minería, la difícil compatibilidad entre la actividad minera y agraria y la generación limitada de empleos locales.

\section{Demandas}

Las principales demandas de los pobladores fueron:

- Los dirigentes piden la demolición y retiro de la Planta de Molibdeno, de la Planta de Filtros y del Almacén de Concentrados porque no estaban considerados en la propuesta inicial y son altamente contaminantes.

- Otra solicitud es que la empresa minera incluya como zonas de influencia las comunidades de Cotabambas y Grau, y también los pueblos por donde pasará la línea eléctrica y el transporte de carga pesada de los minerales hasta Matarani.

- La anulación de las modificaciones del estudio de impacto ambiental.

- Retiro de funcionarios mineros responsables del cambio del EIA a espaldas del pueblo.

- Cierre de emisoras radiales de la empresa MMG Limited.

- Renegociación de las tierras comunales de la zona de influencia minera. Al respecto hay muchas irregularidades producto del poder de las empresas mineras y de la ausencia del estado.

- Retiro de las oficinas Willana Wasi (casas informativas) de Cotabambas y Grau.

- Aporte del 10\% de las utilidades para un fondo social, etc.

\section{El Conflicto: Crónica de los Acontecimientos}

La exposición que sigue se divide en tres partes: 5.1) hechos ocurridos en el 2015 antes del inicio del paro indefinido, 5.2) acontecimientos principales del conflicto, cubren el lapso 25 de setiembre al 6 de octubre y 5.3) hechos posteriores a esta última fecha que explican el desinterés del gobierno nacional y de la empresa para solucionar los problemas centrales que afectan a los pobladores de las comunidades.

\subsection{Hechos ocurridos antes del paro indefinido}

Estos hechos son los antecedentes más próximos al estallido del conflicto porque los más lejanos se remontan al 2004, año en que llega Xstrata. Aquí solo se reseńan algunos acontecimientos ocurridos en el 2015 antes del inicio del paro indefinido del 25 de setiembre, información detallada, al respecto, se encuentra en los reportes mensuales de conflictos mineros de la Defensoría del Pueblo (DP).

06-02-15. Se realizó un paro de 72 horas en Challhuahuacho, con la retención temporal de un grupo de empleados de una empresa subcontratista por 
incumplimientos de acuerdos suscritos con Xstrata. A partir de un pliego de reclamos de 30 puntos.

28-02-15. Se constituyó una Mesa de Desarrollo en dicho distrito promovida por el gobierno nacional, el gobierno local, las organizaciones sociales (promotoras del paro) y las comunidades campesinas. A mediados de julio, tres de los cuatro de los sub grupos de trabajo que contaban con acuerdos sobre proyectos de infraestructura y productivos dejaron de funcionar. Frente a estos acuerdos se genera descontento en la población porque consideran que no se ha recogido su opinión sobre proyectos. A partir de ello, logran acordar con las autoridades establecer una priorización de los mismos tomando en cuenta su opinión y necesidades (DP).

18-03-15. Asesinaron a Alberto Roque, alcalde del distrito de Mara. Aparentemente se trataría de un acto delincuencial, indicando el aumento de la criminalidad en Apurímac. Aunque también algunos medios de comunicación habrían vinculado su muerte con la presencia de actores con poder económico y político, que estuvieron promoviendo procesos de corrupción de funcionarios y cooptación de dirigentes. Alberto Roque habría informado antes de morir que realizaría una reunión de rendición de cuentas donde informaría sobre el estado de las finanzas de la municipalidad (DP).

En marzo 2015, representantes de 47 comunidades de Apurímac, que agrupan a un promedio de 40,000 pobladores de las provincias de Cotabambas y parte de Grau en Apurímac, hicieron una marcha de sacrificio en la capital llevando un pliego de reclamos en el que demandaban el respeto al medio ambiente y a los derechos humanos, porque Las Bambas les sonaba a Conga y a Tía María (Velaverde 10-05-16).

11-04-15. Se realizó una reunión entre dirigentes y funcionarios del MINAM y del MEM donde los dirigentes expresaron su malestar por las modificaciones al EIA realizadas sin participación ciudadana ni consulta, acordándose que los responsables de ambas carteras irían a la provincia de Cotabambas para explicar dichas modificaciones y sobre todo, como se iba a garantizar la protección de las fuentes de agua y los derechos de las comunidades (DP).

01-05-15. Se llevó a cabo la primera sesión del Comité de Seguimiento y Desarrollo Integral del distrito de Challhuahuacho (CSDCH), con el objeto de elegir la presidencia y secretaría técnica, así como aprobar el reglamento correspondiente. Participaron representantes de la ONDS, MINEM, MINAGRI, MVCS, MINSA, MINAM, MIDIS y de la Federación de Jóvenes Paquis Waraka, Gobierno Regional de Apurímac, la Municipalidad del Distrito de Challhuahuacho y la empresa MMG Las Bambas. Se acordó nombrar presidente del CSDCH al MINEM y como Secretaría técnica a la ONDS. Asimismo, se acordó aprobar su reglamento, el cual consta de once artículos adicionales (DP).

04-06-15. Funcionarios del MINAM y el MEM intentaron realizar la reunión sin la presencia de los ministros lo que no fue aceptado por las organizaciones sociales debido a que ese no había sido el acuerdo adoptado anteriormente.

12-06-15. Se reunió un Congreso Provincial de Líderes y Autoridades de la provincia de Cotabambas en la comunidad de Huancuire, distrito de Coyllurqui, en donde se acordó una plataforma de lucha, cuyo principal punto estaba referido al tema de no haber sido informados ni consultados sobre modificaciones sustanciales realizadas al EIA del proyecto de las Bambas. En este tema se menciona explícitamente, la eliminación del mineroducto y el traslado de la planta de molibdeno a la cabecera de cuenca. En esta reunión se formó el comité central de lucha de la provincia de Grau y Cotabambas, cuyo liderazgo fue depositado en la señora Virginia Pinares Ochoa del distrito de Haquira, además se formaron comités de lucha por cada distrito. (D.P.).

30-06-15. En un comunicado, un número importante de organizaciones reiteraron su solicitud al gobierno nacional para sostener una reunión con la participación de ministros y la empresa MMG con la finalidad de esclarecer los cambios en el EIA; a julio de 2015 esta reunión se había postergado por cuarta vez por la ausencia de los ministros (Flores 2016).

En agosto de 2015, se instaló el comité de seguimiento para monitorear y evaluar el cumplimiento de los acuerdos alcanzados en las distintas submesas (Flores 2016).

05-09-15. Las organizaciones civiles y campesinas agrupadas en el Comité Central de Lucha de las provincias de Grau y Cotabambas, reunidas en asamblea, decidieron convocar a un paro indefinido, para denunciar la modificación del EIA «sin respetar los procedimientos de participación ciudadana y el derecho a la información». Los líderes dejaron sentado en el acta de la reunión que, en cinco oportunidades, invitaron a los representantes de la empresa MMG y el 
Ministerio de Energía y Minas para que les expliquen los cambios realizados en el estudio de impacto ambiental, pero no fueron escuchados. El inicio del paro indefinido se fijó para el 25 de setiembre (DP).

12-09-15. En la comunidad campesina Huancuire del distrito de Coyllurqui, se reunieron organizaciones de base y frentes de defensa de las provincias de Cotabambas y Grau y acordaron iniciar un paro indefinido el 25 de setiembre debido a la falta de información respecto a las modificatorias al estudio de impacto ambiental para el proyecto Las Bambas, entre otros puntos.

La Defensoría del Pueblo mediante el oficio No 279 solicitó información al MINEM sobre las modificaciones al estudio de impacto ambiental del proyecto Las Bambas y los mecanismos de participación realizados.

24-09-15. El gobierno aprobó una norma a fin de que el Ejército ingresara a la zona para brindar apoyo a la policía.

El recuento anterior es suficiente para demostrar la vigencia y continuidad de los problemas estructurales en Las Bambas. También hay que resaltar: quienes manejan y deciden cómo resolver los problemas o cómo evitar su solución son el gobierno nacional y la empresa minera. Lo que se comprueba a lo largo del trabajo.

\subsection{Hechos ocurridos entre el 25 de setiembre al 6 de octubre}

Aquí se describen los acontecimientos más importantes del conflicto que concitan la atención nacional e internacional. Se extiende hasta el 6 de octubre porque este día se reúne la Comisión de Alto Nivel del Gobierno Nacional con autoridades locales de los distritos de la provincia de Cotabambas. El comportamiento del gobierno en este corto lapso es muy especial, está condicionado porque Lima era entonces «la capital económica del mundo», por la reunión del BM y el FMI. Después del 6 de octubre, el conflicto social en Las Bambas entró en una etapa de tensa calma. El gobierno tiene el control con el estado de emergencia y la presencia de la PNP y militares.

25-09-2015. Se inició el paro anunciado. Se cerraron las vías de acceso hacia Las Bambas y Mara, y en el puente de acceso a Tambobamba y Challhuahuacho así como hacia Haquira. No hubo tránsito de vehículos y se formaron piquetes en varios puntos de las vías. Desde este día rige la Resolución Suprema 200-2015 del Ministerio del Interior, que autoriza la intervención de las Fuerzas Armadas en las provincias de Cotabambas y Grau, en Apurímac, también en las provincias de Chumbivilcas y Espinar, en Cusco.

26 y 27-09-15. El paro continúa, pero no hay acontecimientos perturbadores del orden público.

28-09-2015. Se produjeron violentos choques en los alrededores de la comunidad de Fuerabamba, distrito de Challhuahuacho, provincia de Cotabambas. Bordeando el mediodía, unos dos mil comuneros ${ }^{3}$ se reunieron a la altura del puente Challhuahuacho en un mitin improvisado en el que se animó a continuar las protestas. Cientos de policías observaban la reunión desde un punto alejado. De pronto ellos (los policías) dispararon gases lacrimógenos y los grupos se dispersaron. Según Henry Vásquez. Representante de Cooperacción, en determinado momento un grupo nutrido de manifestantes acorraló y persiguió a un pequeño contingente de policías, estos decidieron replegarse. Hay versiones de que dos agentes cayeron a un barranco y resultaron heridos. Según el vocero del Frente de Defensa de los Intereses de la Provincia de Cotabambas, Jaime Osorio, negó que hayan hostigado a los policías, otros testigos lo contradicen. El vocero mencionado afirmó: «Se ha agotado el tiempo de espera. No detendremos esta protesta hasta que el Estado dé la cara. Que vengan los Ministros, que venga el Ejecutivo». Por la noche el humo de los pastizales incendiados obligó a los agentes a replegarse. Los pobladores se concentraron en la Posta Médica de Challhuahuacho para conocer el estado de los compańeros heridos. El saldo de los enfrentamientos fue tres muertos, veintitrés heridos ( 15 civiles y 8 policías) y 18 personas detenidas. El enfrentamiento violento se produjo en los alrededores de la comunidad de Fuerabamba, distrito de Challhuahuacho, provincia de Cotabambas.

Sobre los acontecimientos de este día La República (29-09-15) informó así: «Los enfrentamientos dejaron un saldo de tres personas fallecidas: Exaltación Huamaní Mío (32), Alberto Cárdenas Challco (24) y Beto Chahuayllo Huillca (39).

3 «En horas de la tarde, cuando aproximadamente 10,000 manifestantes se encontraban reunidos cerca del Puente Challhuahuacho, la policía en un número aproximado de 2,000 efectivos, intentó repelerlos utilizando bombas lacrimógenas» (CooperAcción 2015: 17). 
Al mediodía, delegaciones de varias comunidades de las provincias de Cotabambas y Grau tuvieron una reunión en Challhuahuacho, el principal punto que se trató fue la falta de atención pública a la medida de fuerza. Algunos plantearon tomar las instalaciones de Las Bambas, sin tener eco en otros dirigentes. El primer acuerdo fue consultar a las bases. Sin embargo, un grupo de jóvenes subió a un cerro aledaño. Para la policía esto fue un intento de ingresar al campamento, y dispararon bombas lacrimógenas lo que originó un enfrentamiento por dos horas aproximadamente. "Al promediar las cinco de la tarde, corrió la versión de varios heridos de bala y los ciudadanos enardecidos ingresaron al campamento antiguo de Las Bambas».

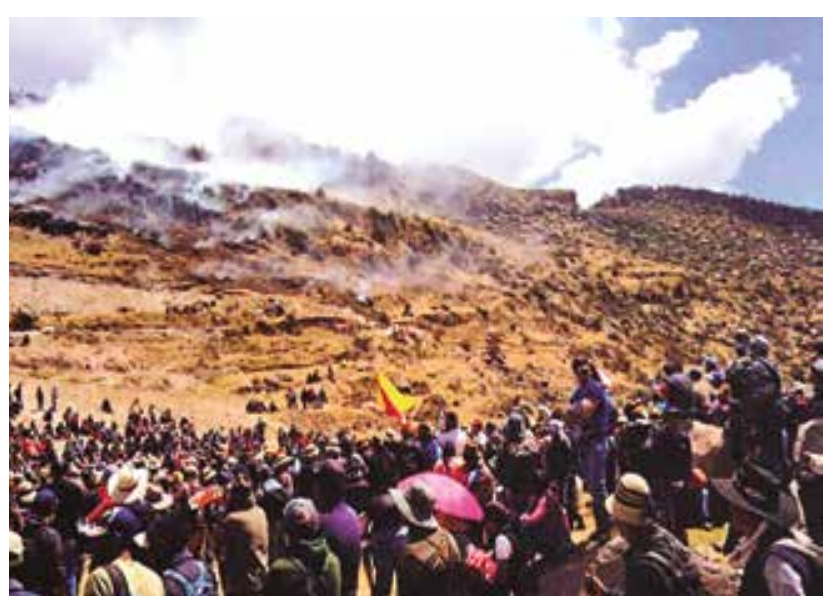

Algunas declaraciones relacionadas con los acontecimientos de ese día fueron: 1) «Primero, lamento la pérdida de vidas (...) el Estado no ha abandonado a la población de Challhuahuacho (...) pido a los dirigentes que encaucen democráticamente sus protestas» (Ollanta Humala). 2) «Definitivamente, han entrado a la mina. Una cosa es una manifestación pacífica y otra es una agresión a la mina. Aparte habían bloqueado las carreteras (...). La policía tiene que defenderse» (José Luis Pérez Guadalupe, Ministro del Interior). 3) «No podemos ser ingenuos. No hay que ser adivinos para poder determinar que se están aplicando los mismos procesos que se han dado en otras regiones (...). Hay gente (infiltrada) de otras zonas» (Wilber Venegas, Gobernador Regional de Apurimac. 4) «Las Bambas es un proyecto que durante diez años ha convivido con las comunidades. En la última etapa de construcción, han surgido inconvenientes que espero sean resueltos» (Antonio Medina, Congresista por Apurimac), etc.
29-09-2015. El Frente de Defensa envió carta al Ejecutivo y empresa MMG para dialogar. Se pide levantar el estado de emergencia, liberar a los detenidos y anular el EIA modificado. Consorcio Chino y el MEM señalaron que las modificaciones al EIA benefician a la población.

Pese a la declaración de emergencia, un grupo de jóvenes intentó marchar a la Plaza Mayor del pueblo. La policía los dispersó lanzando bombas lacrimógenas y haciendo disparos al aire. Hubo un enfrentamiento durante casi 15 minutos entre manifestantes y la policía. Un poblador resultó herido en el brazo por el impacto de una bomba lacrimógena. También hubo enfrentamientos en la zona de Mota, de la Comunidad de Pamputa, del distrito de Challhuahuacho. Dos vehículos de empresas ligadas a la mina fueron incendiados. Se desarrollaron marchas. Rodolfo Abarca, Presidente del Frente de Defensa de los Intereses de la Provincia de Cotabambas, niega que los comuneros que apoyan la protesta sean antimineros o estén contra Las Bambas «es una protesta anunciada con anticipación. $\mathrm{Ni}$ la empresa ni el gobierno quisieron dialogar» (La República 30-09-15).

El Premier Pedro Cateriano, condenó los actos de violencia y llamó a la calma. Las Bambas «implicará para el próximo año un incremento del PBI del 1.4 $\%$ de crecimiento para el país, razón por la cual no podemos dejar que un grupo de gente, dirigido con fines políticos entorpezcan un proyecto que a lo largo de estos años se desarrolló con normalidad (...) Hemos venido dialogando con las partes y por esta razón hemos ido avanzando en este importantísimo proyecto para el país. Que se encuentra en el 98\% de su ejecución».

El Gerente de Medio Ambiente del Proyecto Las Bambas, Antonio Mendoza, señaló que «han tenido el apoyo de las comunidades y que Las Bambas tienen voluntad de dialogar en todo momento".

En una reunión realizada en el Estadio de Challhuahuacho, los dirigentes de la provincia, distritos y comunidades acordaron seguir con la huelga hasta que se atienda sus reclamos. Volvieron a rechazar el EIA aprobado con el visto bueno del Alcalde de Cotabambas Odilón Huanaco y otros ex alcaldes. Representantes del Ejecutivo, Alcaldes de Cotabambas y Challhuahuacho y el Gobernador Regional, Wilber Venegas, se reunieron en el MEM. No se pusieron de acuerdo. Se espera que el día siguiente (30-09-15) se conforme una Comisión de Alto Nivel. Llegarán a Lima otros alcaldes de la zona. Las calles de Challhuahuacho 
se han convertido en comedores populares con ollas comunes para cerca de 7,000 campesinos de la localidad. No hay transporte público. No se puede entrar a Challhuahuacho.

30-09-15. Se reunieron el Frente de Defensa de los Intereses de la Región Apurímac, el Frente de Defensa de la Provincia de Abancay, organizaciones de base, sindicatos del GORE y de sus sectores, construcción civil y la comunidad campesina Iscahuaca. Acordaron hacer una movilización el 1 de octubre, y un paro de cuarenta y ocho horas los días 5 y 6 de octubre, en apoyo y solidaridad con la provincia de Cotabambas, entre otros puntos.

El mismo día, representantes de la ONDS 4 , los titulares del MINEM, MINAM, Transportes y Comunicaciones, Interior, MIDIS, MVCS, y otros representantes del Poder Ejecutivo se reunieron con los alcaldes distritales de Challhuahuacho, Haquira, Cotabambas, Coyllurqui y el alcalde provincial de Cotabambas, en las oficinas de la PCM.

Por otra parte, el presidente del Frente de Defensa de Cotabambas, Adolfo Abarca, anunció una tregua de 24 horas en las protestas a fin de que se instale una mesa de diálogo con la participación de los Ministros de Energía y Minas, del Ambiente y el Presidente del Consejo de Ministros. Este pedido lo hicieron por escrito y fue dirigido al Presidente del Consejo de Ministros. También solicitaron el levantamiento del estado de emergencia y la liberación de los detenidos.

01-10-15. Después de los hechos de violencia del 28-09-15, varios dirigentes, para proteger su integridad salieron de Cotabamabas. El 01 de octubre estaban en Cusco «Poder conversó con ellos... En la reunión estuvieron Rodolfo Abarca, Presidente del Frente de Defensa de la Provincia de Cotabambas; Ronald Bello, Presidente del Frente de Defensa de Tambobamba; Cosme Bolívar y José Portugal, representantes de las 17 comunidades del área de influencia directa (AID) del Proyecto Las Bambas; y Alem Torre, Asesor de los dirigentes, entre otros» (Navarro 2015).

1 y 2-10-15. Una delegación de la Coordinadora Nacional de Derechos Humanos, presidida por Jorge Bracamonte viajó a Cotabambas para documentar la situación de los derechos humanos durante los días

4 En el trabajo se usa los nombres de instituciones y cargos que eran vigentes en el ańo 2015. Algunos de ellos han cambiado; por ejemplo, la Secretaría de Gestión y Diálogo, ha reemplazado a lo que fue la Oficina Nacional de Diálogo y Sostenibilidad; asimismo, al Presidente Regional, hoy se le denomina Gobernador Regional, etc. de protesta. Se volvieron a reunir en las oficinas del MINEM.

02-10-15. Se reunieron en las oficinas del MINEM (Lima) los alcaldes de la provincia de Cotabambas y seis ministros de estado. Acordaron instalar una mesa de diálogo con las autoridades municipales y representantes de las diferentes organizaciones de la sociedad civil. Fijaron además como fecha de la primera reunión de la mesa de diálogo el 6 de octubre, en la Municipalidad Distrital de Coyllurqui y como primer punto a tratar la explicación del Informe Técnico Sustentatorio que modifica el estudio de impacto ambiental del proyecto Las Bambas. El presidente del Frente Único de Defensa de los Intereses de Cotabambas, Rodolfo Abarca, considera que «esa decisión de los alcaldes es una forma de traición» (La República 03-10-15). Por otra parte, el premier, Pedro Cateriano, calificó como contraproducente impulsar la censura contra los ministros de Energía y Minas, Interior y Ambiente en el congreso, en medio del conflicto minero de Las Bambas (La República 02-10-15). Doscientos soldados se instalaron en el campamento minero e hicieron prácticas de control de multitudes con escudos similares a los que usan la policía (El Comercio 02-10-15). En la comunidad de Congota, entre Challhuahuacho y Mara, manifestantes bloquearon una carretera, pese a la tregua de 72 horas anunciada el martes (El Comercio 02-10-15).

03-10-15. Según el presidente Frente de Defensa de Tambobamba, Ronald Bello, el ejército entró a la comunidad de Tambuya buscando a los dirigentes.

04-10-15. Las organizaciones sociales de las provincias de Cotabambas, Grau y Chumbivilcas acordaron no participar en la mesa de diálogo a realizarse en Coyllurqui entre alcaldes y el gobierno nacional. Consideran que no pueden ser parte de esa mesa mientras esté vigente el estado de emergencia y los dirigentes sean víctimas de persecución.

05-10-15. Pobladores de la provincia de Abancay realizaron una marcha en respaldo a la protesta que cumplen las provincias de Cotabambas y Grau.

6-10-15. Se llevó a cabo la reunión programada en la Municipalidad Distrital de Coyllurqui. En esta reunión estuvieron presente ministros, viceministros, otros funcionarios, alcaldes. Además representantes de comunidades campesinas de la zona de influencia del PMLB. No asistieron dirigentes de organizaciones sociales de los frentes de defensa de Cotabambas y Grau. Ellos afirman que los cambios al EIA se 
hicieron de manera inconsulta. El gobierno y la empresa minera sostienen lo contrario. Los ministros presentes fueron: Rosa María Ortiz (Energía y Minas), Manuel Pulgar-Vidal (Ambiente), Milton Von Hesse (Vivienda, Construcción y Saneamiento), José Luis Pérez Guadalupe (Interior); todos ellos constituyeron la Comisión de Alto Nivel del Ejecutivo. También asistieron seis alcaldes: Odilón Huanaco (Cotambambas, provincia), Leoncio Mendoza (Coyllurqui), Adiel Sota (Mara), Antolin Chipana (Challhuahuacho), Isaac Anaya (Haquira), Fortunato Mantilla (Cotabambas, distrito). Además participaron de la reunión el gobernador regional, Wilber Venegas, y representantes del Ministerio Público y la Defensoría del Pueblo. Después de tres horas y media, aproximadamente, de conversaciones se suscribió un acta con cuatro acuerdos. Esencialmente fueron:

- Los ministros se comprometen a proponer el levantamiento del estado de emergencia una vez que los representantes de la población hayan levantado la paralización.

- El MVCS brindará viviendas a las familias de las tres víctimas fatales de los sucesos del 28 de septiembre. Adicionalmente, el sector Educación y los programas sociales identificarán medidas concretas para atender a estas familias.

- El Ministerio de Salud se compromete a financiar los gastos de recuperación de los heridos.

- Se realizarán talleres informativos en cada uno de los distritos de Cotabambas para informar sobre el Informe Técnico Sustentatorio. Se fijó fechas para esos talleres en el mes de octubre: 10 en Challhuahuacho, 11 en Haquira, 17 en el distrito de Cotabambas, 18 en Coyllurqui, 19 en Tambobamba y 20 en Mara.

En relación a los talleres informativos programados, los de Challhuahuachoy Haquira fueron reprogramados para los días 5 y 7 de noviembre respectivamente. El de Coyllurqui fue reprogramado para el 8 de noviembre. Los talleres de Cotabambas, Tambobamba y Mara se suspendieron. Las reprogramaciones e incumplimientos continuaron en los meses siguientes.

En la Mesa de Diálogo también se explicó el Informe Técnico Sustentatorio (ITS), el cual según el MEM cumplió con las normas. Añadieron que el ITS sí fue socializado en el área de influencia directa de Las
Bambas y en la ruta del transporte de los minerales. Guillermo Shinno, señaló que la empresa presentó en 2013, el ITS y que los posibles impactos ambientales no son sustanciales.

Los campesinos y las autoridades exigieron que para seguir con el diálogo debía garantizarse el levantamiento del estado de emergencia y la liberación de los comuneros Edwar Quispe Ccuno y Javier Mamani Coaquira.

\subsection{Hechos ocurridos después del 6 de octubre}

La reunión mundial del BM y del FMI en Lima, se realizó entre el 05 y 11 de octubre del 2015, cumplido este evento, el gobierno nacional dejó a un segundo plano el problemas de las Bambas, no se tomó ninguna medida significativa a favor de los pobladores de las comunidades. Se producen una sucesión de mesas que mecen, de promesas, postergaciones, incumplimientos, ausencias, avances, retrocesos, etc. Que finalmente terminan en el estallido del 14 de octubre del 2016. El recuento que sigue ilustra esta situación.

El 19 de octubre, se reunieron en la sede de la PCM en Lima los representantes del Poder Ejecutivo con los alcaldes distritales y provincial de Grau. Participaron también dirigentes comunales y organizaciones sociales del distrito de Progreso. Acordaron desarrollar un cronograma de trabajo, que primero atienda los proyectos de las municipalidades y la instalación de una mesa de diálogo para el 11 de noviembre. Se acordó también realizar una reunión informativa sobre la modificación al EIA del proyecto Las Bambas y una reunión de las autoridades locales con la empresa MMG. Al cierre de este reporte no se confirmó la fecha de ambas reuniones (DP).

El 28 de octubre, organizaciones sociales y comunales de Cotabamba y Grau se reunieron en la Municipalidad del centro poblado Pisaccasa. Acordaron el levantamiento del paro en Cotambambas y Grau.

El 29 de octubre, los ministros del Interior, Energía y Minas, Vivienda y Salud informaron en Tambobamba sobre el levantamiento del estado de emergencia declarado en las provincias de Cotabambas, Grau, Andahuaylas y Chincheros del departamento de Apurímac y en las provincias de Chumbivilcas y Espinar del departamento de Cusco, mediante el decreto supremo No 068-2015-PCM.

En Noviembre se inicia "la marcha blanca» que es el período de prueba o producción pre-comercial. El 
primer concentrado de cobre fue producido el 26 de noviembre de 2015.

En Enero de 2016, MMG, según el Observatorio de conflictos mineros (OCM), realizó el primer embarque de cobre.

29-02-16. Se instaló la mesa de diálogo de la provincia de Cotabambas; después del estallido del conflicto. En todo ese tiempo no se atendió las demandas básicas de los pobladores. En esta mesa hay cuatro ejes de trabajo: Medio Ambiente y Modificatoria del EIA, Derechos Humanos, Desarrollo Sostenible y Responsabilidad Social Empresarial en las Áreas de Influencia.

21-04-16. Se iniciaron las sesiones temáticas de la nueva Mesa de Diálogo de Cotabambas; es decir, seis meses después de concluidas el paro indefinido.

12-08-16. Unos 400 comuneros se enfrentan a la PNP tras bloquear la vía utilizada para el paso de camiones de la mina (El Comercio 16-10-16).

14-10-16. Enfrentamiento entre comuneros de Allahua, Pumamarca, Choquecca Antuyo y Quehuira con la PNP. Muere por impacto de bala Quintino Cereceda. Empieza otra etapa del conflicto social en Las Bambas.

\section{Análisis y discusión de los resultados}

El conflicto social de setiembre del 2015 en Las Bambas es el resultado de muchos conflictos anteriores. La descripción de él muestra la complejidad del problema, por eso aquí se presentan algunas entradas que contribuyan al análisis y discusión del mismo: 6.1 Las Bambas: ¿Modelo de buenas relaciones?, 6.2 Nuevos dueños y cambios en el EIA, 6.3 Diálogos sin resultados, 6.4 Mesas que mecen.

\subsection{Las Bambas: ¿Modelo de buenas relaciones?}

El PMLB se ha presentado ante el Perú y el mundo como un ejemplo global de buenas relaciones entre el Estado, la empresa minera y las comunidades. Las Bambas había sido considerado el emblema de los proyectos mineros en el que concurrían el diálogo, la responsabilidad social empresarial y la apertura a la comunidad (La República 02-10-15). Este entendimiento habría sido una constante desde el 2004 hasta setiembre del 2015, fecha en la que estalló el conflicto. Esta percepción no se ajusta cabalmente a la realidad. $\mathrm{Al}$ respecto:

"Hasta hace poco, cuando le preguntabas a una autoridad de gobierno por un ejemplo de paz y amor entre la minería y su entorno, invocaban a las Bambas. Tanto Rosa María Ortiz, ministra de Energía y Minas, como Manuel Pulgar-Vidal, del Ambiente, me han respondido igual cuando les hice la pregunta. Y ahora ¡cuatro civiles muertos, policías heridos, estado de emergencia y diálogos con espíritus caldeados! Entonces, no había paz y amor en las Bambas. Era la calma antes de la tormenta, el volcán dormido a punto de despertarse, el conflicto no del todo prevenido por las unidades de prevención de conflictos que, si no lo paramos, nos costará cientos de millones de dólares» (Vivas, 2015).

Con la llegada de Xstrata a Cotabambas y Grau (Apurímac) también llegó el conflicto con las comunidades. Xstrata tuvo la iniciativa de dar, en adelanto, millones de dólares. El 31-08-04 se efectuó la licitación pública internacional, en la cual compitieron Xstrata de Suiza, Compahia Vale do Rio Doce de Brasil, BHP Billiton Tintaya de Australia y Phelps Dodge Corporation de EE.UU. La ganadora fue Xstrata de Suiza con una oferta de US\$ 121 millones de dólares, tres veces más que el precio base (US\$ 40 millones). De acuerdo a las bases del concurso, parte del precio pagado por la empresa ganadora, US\$ 45.5 millones fue a un fideicomiso que debió destinarse a beneficiar a las comunidades. Hubo una campaña de información intensa que mostraba las bondades del PMLB, pero las comunidades nunca tuvieron una información transparente de los impactos que podía ocasionar la actividad minera. Los problemas que surgían no fueron solucionados, solo se postergaban así la acumulación de los mismos terminaron en nuevos estallidos.

¿Qué hizo el gobierno y la empresa minera para lograr esta supuesta armonía con las comunidades? Se empieza a desarrollar un plan de trabajo poniendo énfasis en programas sociales. Se destaca que el PMLB es el primero en el país, que aporta beneficios desde su implementación. Esto no ocurría antes en la gran minería que hacía aportes solo después que el proyecto entraba en la etapa de explotación. A fines del 2008, el Consejo Ejecutivo del fideicomiso decidió transformar su estructura legal y organización, y se creó la Asociación 
Civil Fondo Social Las Bambas (FOSBAM) que tuvo como propósito financiar, planificar y ejecutar programas de carácter social para la realización de proyectos de desarrollo sostenible en beneficio de las localidades que se encuentran en el ámbito de la zona de influencia del Proyecto Minero.

Antes de FOSBAM tuvo un rol protagónico en el PMLB Proinversión, De Althaus (2015) destaca que el proyecto fue promovido por Proinversión bajo la dirección de Jorge Merino que envió equipos a las comunidades y distritos de la provincia de Cotabambas y también a Abancay para explicar el proyecto y recoger las demandas y preocupaciones de la población. Además, según el autor antes citado, Merino, desde Proinversión, lideró en el terreno hasta el 2011, la implementación de los compromisos y el trabajo en las comunidades, hizo una labor casa por casa llevando cocinas mejoradas, paneles solares y explicaciones acerca del proyecto; el alejamiento (de Merino) originó un vació que, según De Althaus, dejó el campo libre a los opositores del proyecto. Sobre el papel que juega Proinversión en Las Bambas, también hay abundante información; pero, al igual que FOSBAM, su actuación esencial, fue pro empresa minera y pro gobierno nacional sin descartar que ambas instituciones contribuyeron también a crear esa imagen de relaciones armoniosas entre los actores del PLMB, que en esencia fue una falacia.

\subsection{Nuevo dueño y cambios en el EIA}

Otro motivo relacionado con el conflicto es el cambio de dueño de los yacimientos mineros que, a su vez, generará cambios en el EIA original aprobado en 2011. En el 2013 se anunció la fusión entre Xstrata y Glencore. Esta fusión debió contar con la aprobación de los cuerpos regulatorios de la Unión Europea, Reino Unido, Sudáfrica y China. Para evitar monopolios, China aceptó la fusión antes mencionada a cambio de la venta de Las Bambas a un consorcio estatal chino (MMG Limited). Esa venta costó US\$.7 mil millones. Antes, Xstrata operaba en Apurímac (Las Bambas) y en Cusco (Tintaya, Antapaccay); ahora la empresa china solo explotará Las Bambas en Apurímac. Este hecho explica los cambios en el EIA original. Del 2013 al 2014 se hacen cinco modificaciones.

«Dos modificaciones se han realizado por el procedimiento regular del EIA, que requieren de un procedimiento muy similar al de la aprobación del EIA, y tres se han realizado mediante el procedimiento de aprobación del ITS, procedimiento simplificado, con pocas exigencias y con un plazo de aprobación

AREA DE INFLUENCIA SOCIAL DIRECTA (AISD) CORRESPONDIENTE A LA SEGUNDA MODIFICACIÓN DEL EIA DEL PROYECTO LAS BAMBAS

\begin{tabular}{|c|c|c|c|}
\hline \multirow{2}{*}{$\begin{array}{l}\text { COMUNIDADES CAMPESINAS Y } \\
\text { CENTROS POBLADOS DEL AISD }\end{array}$} & \multicolumn{3}{|c|}{ ÁREA DE INFLUENCIA SOCIAL INDIRECTA (AISI) } \\
\hline & DISTRITO & PROVINCIA & REGIÓN \\
\hline $\begin{array}{l}\text { C.C. Carmen Alto de Challhuahuacho } \\
\text { C.C. Fuerabamba } \\
\text { C.C. Manuel Seoane Corrales } \\
\text { C.C. Quehuira } \\
\text { C.C. Chuycuni } \\
\text { C.C. Chicñahui } \\
\text { C.C. Huanacopampa } \\
\text { C.C. Ccasa } \\
\text { C.C. Ccahuapirhua } \\
\text { C.C. Sacsahuillca } \\
\text { C.P. Challhuahuacho } \\
\text { C.C. Pamputa } \\
\text { C.C. Huancuire } \\
\text { C.C. Pumamarca } \\
\text { C.C. Choqueca Antio } \\
\text { C.C. Chumille } \\
\text { C.C. Cconccacca }\end{array}$ & Challhuahuacho & Cotabambas & 更 \\
\hline
\end{tabular}

Fuente: Minera Las Bambas, citado en el trabajo de Navarro (2015) 
tan solo en 15 días hábiles. La primera modificatoria realizada por procedimiento regular y la primera realizada por ITS se han tramitado de manera paralela. La segunda modificatoria realizada por procedimiento regular se inició a menos de un mes de aprobado el segundo ITS. Estas modificatorias pudieron manejarse de manera conjunta para visualizar los cambios y sus impactos de manera más integral» (Cooperacción, 2015).

La tesis que sostiene el gobierno y la empresa minera es que las cinco modificaciones no fueron sustantivas y por eso en tres oportunidades se aplicó el Informe Técnico sustentatorio (ITS). Los dirigentes de las organizaciones sociales sostienen un punto de vista opuesto y está ilustrado en las citas que siguen: 1) «La empresa cumplió con informar a las autoridades. Pero por parte del gobierno no hubo intención de difundir el tema en las mesas de diálogo» (Paul Pilco. Semana Económica $\left.\mathrm{N}^{\circ} 1489\right), 2$ ) «Si bien los dos cambios realizados bajo el procedimiento de modificación del EIA, habrían tenido mecanismos de participación ciudadana, estos habrían sido poco eficientes ya que la población denuncia no haber sido informada y el no haber manifestado su opinión» (Cooperacción 2015: 19).

La tesis de que las modificaciones no son sustantivas no es sostenible. Bastan algunos hechos para refutarla: 1) Los cambios implican que ciertos componentes del PMLB pasan de una región a otra (de Cusco a Apurímac) y esto es sustantivo. 2) La modificación del sistema de manejo de aguas del depósito de relaves. Se amplía el almacén de concentrados de 20,000 ton. a 47,000 ton. dentro de la planta concentradora. Esta modificación excede los criterios establecidos por la normativa para la aprobación de modificatorias vía ITS: no debe ir más allá del $22 \%$ del diseño inicial. 3) Las modificatorias realizadas en el EIA han disminuido las áreas de influencia social directa. Muchas comunidades y centros poblados han sido excluidos. Este hecho será, inevitablemente, fuente de conflicto en Cotabambas y Grau.

Cuando llega Xstrata a las Bambas, hubo una campaña informativa gigantesca, mostrando las bondades del PMLB. Igualmente, cuando se producen las modificaciones del EIA original también la información debió ser amplia y transparente para toda la población directa e indirectamente afectada, pero fue minúscula y casi exclusiva para las autoridades. Es un problema que hasta hoy no se resuelve a pesar de la reunión del 6 de Octubre del 2015, donde la
Comisión de Alto Nivel prometió solucionar este y otros problemas. Es sospechoso que en reuniones tan importantes efectuadas en Lima y Apurímac, excluyan a las organizaciones sociales y sus dirigentes. «Cotabambas será representada por su alcalde provincial, cinco alcaldes distritales y miembros de las organizaciones de la sociedad civil designados por los alcaldes» (El Comercio 03-10-15).

Con la modificación del EIA de Las Bambas las comunidades del área de influencia directa pasaron de ser 43 a 17, debido al traslado de componentes y a la exclusión de las áreas del mineroducto y Tintaya.

En todos los proyectos mineros se precisa las áreas de influencia directa e indirecta. En Las Bambas, al respecto, hay mucho por aclarar. Inicialmente en la provincia de Cotabambas se consideraba 37 comunidades; en la provincia de Grau solo 12. Con la modificación del EIA de las Bambas, las comunidades del área de influencia directa pasaron de 43 a 17 (Navarro 2015). La Red de Comunicación Regional (RCR) habla de 47 comunidades campesinas de la zona de influencia minera. Hay mucha información que da cuenta de 33 comunidades solo en el distrito de Challhuahuacho. El tema es serio, recuérdese que en el Proyecto Minero Conga solo se tuvo en cuenta 32 comunidades cuando realmente eran más de 200 que serían afectadas directa o indirectamente. En las Bambas este es un problema latente (Ver cuadro anterior).

\subsection{Diálogos sin resultados}

Una de las razones que ha contribuido al estallido del conflicto es el fracaso del diálogo entre los actores del PMLB. Es evidente la asimetría de poder entre ellos. El gobierno nacional y la empresa manejan el diálogo, ellos deciden los temas, el cómo, el lugar, el tiempo, también cuándo lo aceleran o cuándo lo demoran. Un evento mundial ilustra las afirmaciones anteriores. Del 5 al 11 de Octubre del 2015, Lima se convirtió en la «capital económica del mundo». El lunes 5 de Octubre empezó La Gran Reunión Anual del Grupo Banco Mundial y del Fondo Monetario Internacional. Entre los asistentes más destacados se pueden mencionar a Christine Lagarde, Diretora Gerente del FMI; Jim Yong Kim, Presidente del Grupo Banco Mundial; Ban Ki-Moon, Secretario General de Las Naciones Unidades; Alicia Bárcena, Directora Ejecutiva de la CEPAL; Agustín Carstens, Presidente del Comité 
Monetario y Financiero Internacional del FMI; Joseph Stiglitz, Profesor de la Universidad de Columbia, etc. Algunos cálculos hablan de 20,000 invitados de lujo.

Sobre lo ocurrido en Lima y en las Bambas, una opinión crítica:

«La fiesta de las finanzas en Lima se produjo dos semanas después de la tragedia de Las Bambas, un episodio más del viejo libreto de la miseria política del país: por la ineptitud de los ministros y sus funcionarios, no es posible el diálogo y entendimiento con los comuneros y campesinos que defienden sus fuentes de vida, solo después de una cuota de muertos, heridos, detenidos, perseguidos y la intervención del ejército por razones de emergencia. (...) El presidente Humala se puso de lado de la empresa estatal china MMG, con su legislación y sus policías; no tiene cuándo aprender que debiera estar del lado de los comuneros andinos que siguen solos en sus luchas por defender sus tierras, sus nevados, las cuencas de sus ríos, sus lagunas como fuentes de vida y en su reclamo de no ser engañados, ni ninguneados, tampoco de ser tratados como menores de edad.

Los dos acontecimientos de la fiesta de las finanzas en Lima y la muerte en Las Bambas muestran que en Perú la economía tiene poco o nada que ver con la política, la ética y los derechos humanos. Salvo el crecimiento todo es ilusión. El pensamiento único sobre el crecimiento como condición indispensable para el desarrollo capitalista y el discurso del desarrollo como progreso y modernidad, que está enraizado en los gobernantes, funcionarios, empresarios y dueños de los grandes medios de comunicación, sacrifica la vida humana, la ética, y todos los derechos» (Montoya, 2015).

Como se ha señalado anteriormente, el 29 de setiembre el gobierno, declaró el Estado de Emergencia por 30 días en las provincias de Cotabambas, Grau, Andahuaylas y Chincheros (Apurímac) y en las provincias de Chumbivilcas y Espinar (Cusco).

El gobierno tenía que atender dos acontecimientos importantes: uno nacional y otro internacional. Entonces la situación era delicada y necesitaba respuestas urgentes, pues el Perú era el centro de la atención mundial y había que cuidar la buena imagen, por eso el gobierno nacional, contraviniendo un comportamiento tradicional, en el cual usualmente se suele enviar comisiones de avanzada o similares actuó con decisión, presteza, rapidez, y enfrentó el problema de Las Bambas enviando una Comisión de
Alto Nivel integrada por el Premier y cuatro ministros más. Así se logra la "histórica» reunión del seis de octubre en Coyllurqui (Cotabambas) que contribuyó a neutralizar a las organizaciones sociales y sus dirigentes cuyas posibilidades de protestas ya estaban disminuidas por el Estado de Emergencia, la actuación de la PNP y la fuerza militar. Con la presencia de la Comisión de Alto Nivel, el gobierno nacional, quiso demostrar al Perú y al mundo que le interesaba el problema de las comunidades del PMLB, asunto que realmente no había ocurrido desde el 2004, lo que se confirmó nuevamente, al concluir el evento internacional el 11 de octubre. Pasada la coyuntura se volvió a la normalidad: Se acabaron las promesas, las soluciones entraron en un proceso de estancamiento, brillaron las postergaciones, aparecieron nuevas mesas de diálogo y desarrollo, etc., pero los problemas de las comunidades seguían sin solución.

Se debe destacar que las organizaciones sociales de las provincias de Cotabambas, Grau y Chumbivilcas no participaron en la Mesa de Diálogo del 6 de octubre entre alcaldes y gobierno nacional. El acuerdo fue adoptado por los presidentes de los frentes de defensa de las tres provincias. Ellos argumentaron que no pueden ser parte de la mesa de diálogo mientras esté vigente el estado de emergencia y los dirigentes sean víctimas de persecución. El presidente del Frente de Defensa de Tambobamba, Ronald Bello declaró: «La reunión es en Coyllurqui (Cotabambas) y podemos ser detenidos en el camino. Además, si bien no tenemos orden de captura, somos amenazados y el sábado el Ejército entró en la comunidad de Tambuya, buscando a los dirigentes. Eso es persecución» (La República 05-10-15).

Sobre el tema del diálogo en la Mesa de Desarrollo de Cotabambas, Cooperacción (2016) ha realizado un sólido trabajo y de él se destacan algunos puntos que son particularmente importantes:

1) Se carece de reglamento donde se precise entre otros: la finalidad de la mesa, principios del diálogo, participantes, estructura, toma de acuerdos, etc.

2) La presidencia y la secretaría de la Mesa está en manos del MEM y de la ONDS (Oficina Nacional de Diálogo y Sostenibilidad). Se debe considerar una presidencia colegiada con tres miembros y así generar mayor equilibrio en el diálogo de esa mesa.

3) Es notoria la asimetría de poder a favor del Estado y de la empresa minera. Esto ocurre en los cuatro ejes temáticos. No hay diálogo intercultural, hay 
prepotencia y agresión de parte de los representantes de la presidencia y secretaría de la mesa que están en manos del MEM y de la ONDS. Las citas siguientes ilustran el tema de las asimetrías en Las Bambas:

«Las asimetrías de poder se expresan de manera múltiple: (i) falta de conocimientos técnicos de los actores locales para tratar los temas planteados en las mesas; (ii) la duración de la negociación suele ajustarse a las posibilidades de la empresa y del gobierno central, pero en pocos casos, se respetan los tiempos de maduración que requiere la población local; falta de poder económico de los actores locales para sostener una participación permanente y financiar asesorías técnicas, realización de estudios, planteamientos legales por vulneración de derechos, etc. En su lugar, tanto el Estado como la empresa cuentan con recursos económicos y personal técnico suficiente durante la negociación; (iv) el diálogo intercultural casi es ausente en estos espacios (a lo más, se limita a la contratación de un traductor); entre otros» (Flores 2016: 206).

"La presencia de empresas mineras en poblaciones y sociedades rurales, trae como consecuencia mayores asimetrías y muchas veces se profundizan las brechas sociales, económicas y de género. La empresa minera es un actor económico poderoso, que influye en las relaciones sociales y económicas de los espacios locales donde se encuentra. Con la finalidad de mantener un clima de calma y paz social, muchas veces recurre a métodos tradicionales de relación con las comunidades y autoridades locales, generando relaciones de clientelismo, lo que debilita aún más la institucionalidad. Si a ello agregamos la débil presencia estatal, tenemos un panorama en el que las empresas mineras, a los ojos de las comunidades, empiezan a cumplir roles que no les corresponde, lo que no aporta al fortalecimiento de la institucionalidad local» (Cuadros 2010: 85).

4) Hasta ahora, los moderadores de la mesa están parcializados con los intereses del gobierno nacional y de la empresa MMG. Cualquier intervención que atente contra esos intereses es cortada.

5) No siempre se ha dado una participación tripartita; es decir, presencia efectiva de los actores principales: gobierno nacional, empresa y comunidades. En muchas ocasiones solo participaron representantes del gobierno y los alcaldes de la provincia. La actual Mesa de Diálogo de Cotabambas incluye, por primera vez, a las organizaciones sociales y a la empresa. Pero en temas sensibles la posición del gobierno es cerrada, la empresa calla y no se escucha a las organizaciones sociales y sus dirigentes.

6) No hay información objetiva y completa. El MEM no acepta una evaluación independiente de un tercero para esclarecer las cinco modificaciones que se hizo al EIA original.

7) $\mathrm{Ni}$ la empresa ni el Estado asumen su responsabilidad por el impacto negativo que está causando la actividad minera en Las Bambas, ahora en su etapa de operación. Es particularmente notorio el daño que causa el intenso tránsito de camiones (ruido, polvo, congestión, vibraciones, etc.).

8) Aún no hay una relación transparente entre la empresa y las comunidades. La minera MMG debería mostrar de manera pública los compromisos y contratos que tienen con las comunidades de su zona de influencia directa. Así se evitaría tensión en el diálogo, pues al respecto no hay la suficiente transparencia.

9) Es urgente que el gobierno nacional y gobiernos subnacionales capaciten de manera rigurosa en manejo de conflictos y comunicación intercultural al personal que envían a estos procesos de diálogo y negociación, pues están cometiendo serios errores: no se ha dado la palabra a la Defensoría del Pueblo aduciendo que solo es observador, se está cometiendo irregularidades en la redacción de actas, les falta capacidad para la moderación y conducción del diálogo en situaciones de intenso conflicto, es recurrente el maltrato de los moderadores del gobierno contra representantes de las organizaciones locales y comunidades, etc. Sobre las Actas, Luque (2016) afirma «Haremos una lectura de las actas que se han firmado hasta ahora (...) vamos a tener directivas muy claras sobre cómo elaborar una buena acta. Porque ahora es un instrumento débil y que se puede ignorar. La prueba está en el bajo cumplimiento de los acuerdos».

Después del último conflicto (14-10-16) que terminó con la vida de Quintino Cereceda; periodistas, ministros, congresistas, autoridades regionales y locales, etc reconocen que el diálogo efectivo no funcionó en Las Bambas. El trabajo de Cooperacción (2016) demuestra que una razón poderosa para este fracaso fue 


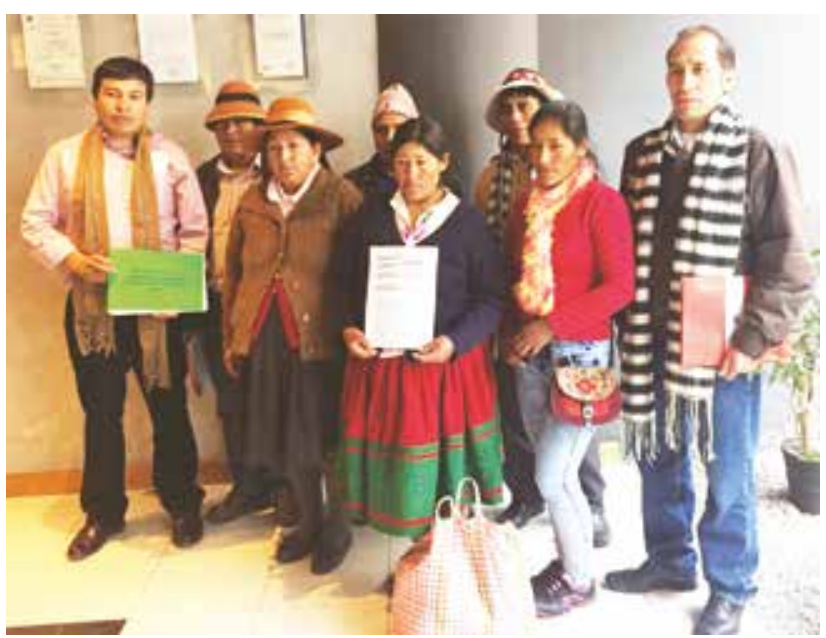

La Bambas: 120 días de estado de emergencia «preventivo». Delegación de Cotabambas en reciente visita a Lima (Foto: CooperAcción).

la asimetría respecto al poder que reina en ese centro minero.

\subsection{Mesas que mecen}

Algunos Congresistas han calificado a las mesas de diálogo y desarrollo como engañamuchachos o mecedoras (Canal de Congreso 19-10-16). Se hace, a continuación una síntesis de cada una de ellas. La información se ha tomado del trabajo de Flores (2016).

\subsubsection{Mesa de Desarrollo de la Provincia de Cotabambas.} El 24 de Julio de 2012 el MEM, decidió implementar la Mesa de Trabajo para el Desarrollo de la provincia de Cotabambas, ésta es más conocida como Mesa de Desarrollo de Cotabambas (MDC). Ella terminó sus funciones en Diciembre de 2013. El nacimiento de esta mesa está condicionada por dos hechos: 1) Inicio de la fase de construcción del PMLB y 2) Los serios conflictos que tenía Xstrata en Tintaya (Espinar) y además por otros similares ocurridos en Cerro Quilish, Santa Ana, Conga, Tía María, etc. En esa mesa hubo dos ausencias fundamentales: a) representantes de organizaciones de la sociedad civil de la provincia y b) representantes de la empresa minera (Xstrata). La mesa estuvo conformada por: a) Gobierno nacional: Un representante del MEM, un representante de la PCM, un representante del MIDIS, un representante del MVCS, un representante del MINAGRI y un representante el MTC. b) Gobiernos Locales: Alcalde provincial y distrital de Cotabambas y los alcaldes distritales de Challhuahuacho, Coyllurqui, Haquira y

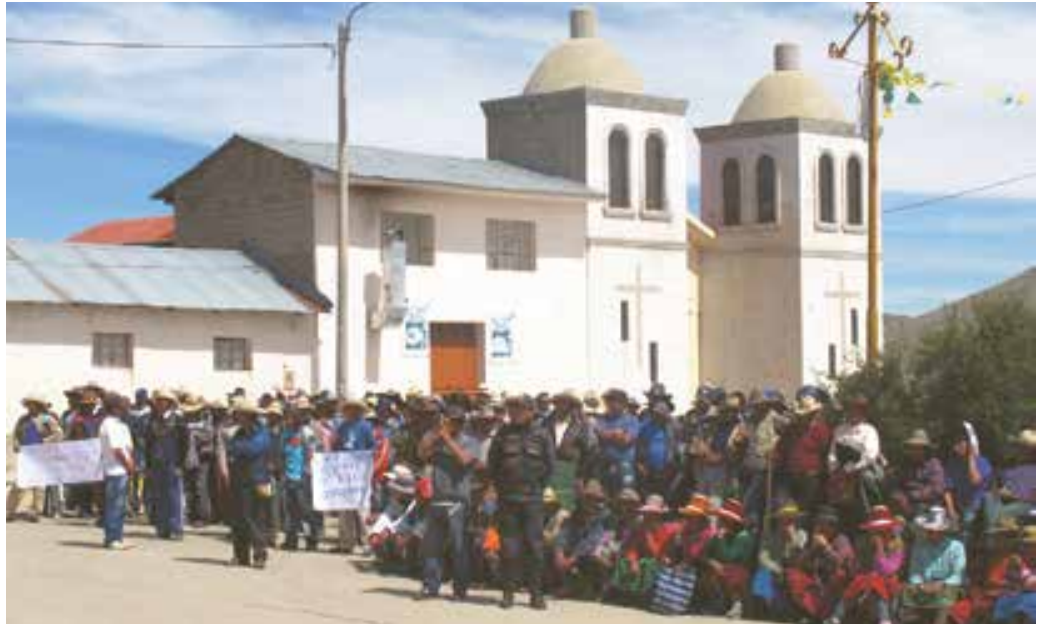

No se han registrado actos que afecten el orden público que justificquen la continuidad del estado de emergencia (Foto: CooperAcción).

Mara. Los integrantes, las ausencias y la transitoriedad de los alcaldes en esta mesa expresan el fracaso de la misma. La gran mayoría de los pobladores de la provincia ignoraban la existencia de esta mesa. Después de revisar las actas de las sesiones de la MDC, Flores (2016) destaca dos características en su dinámica de trabajo: a) una presentación de las principales labores, ya en ejecución, por parte de diversos sectores del gobierno nacional, y b) oferta de nuevos proyectos gubernamentales, ya sea por pedido de las autoridades locales o por iniciativa del gobierno nacional. Todos estos proyectos abarcaron los siguientes sectores: energía y minas, salud, inclusión social, vivienda, agricultura, transporte y comunicaciones, educación, ambiente, interior y Registro Nacional de Identidad.

La MDC permitió articular a tres niveles de gobierno: central, provincial y distrital. Esta articulación, desde entonces, actuó contra los intereses de las comunidades y organizaciones sociales lo que se comprobó antes, durante y después del paro indefinido de setiembre del 2015.

Hay un asunto que traerá serias repercusiones en el futuro, se trata de los paquetes de endeudamiento. Flores (2016) los precisas así:

Primer paquete de endeudamiento de setiembre de 2013 (D.S. $\left.N^{\circ} 235-2013-E F\right)$

El monto correspondiente al principal de la citada operación de endeudamiento interno será íntegramente cancelado en una (01) cuota, el 5 de enero de 2017, y devengará una tasa de interés efectiva anual de $4.65 \%$ sobre el monto efectivamente desembolsado. Los 
intereses serán pagados de forma semestral, calculados a partir de la fecha del primer desembolso.

Segundo paquete de endeudamiento de noviembre de

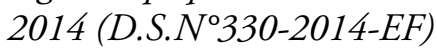

El monto correspondiente al principal de la citada operación de endeudamiento interno será íntegramente cancelado en una (01) cuota, el 5 de enero de 2019, y devengará una tasa de interés efectiva anual de 4.67\% sobre el monto efectivamente desembolsado. Los intereses serán pagados de forma semestral, calculados a partir de la fecha del primer desembolso.

Sobre el primer paquete tiene responsabilidad la MDC y ese es uno de sus grandes pasivos. Sobre este asunto, el gobierno provincial de Cotabambas y algunos gobiernos distritales de la provincia acordaron con el gobierno nacional dos préstamos por adelanto de canon, previo al inicio de operaciones de Las Bambas. El primer préstamo fue por $\mathrm{s} / .47$ millones, el segundo ascendió a s/. 137 millones. Del primer préstamo s/. 24.8 millones serían destinados exclusivamente al distrito de Challhuahuacho; mientras que del segundo préstamo, este distrito recibiría s/. 89 millones del total (Flores et. al. 2017). Pagar estos préstamos retrasará por varios años la entrega del canon. Con la fusión de Xstrata-Glencore y después la compra de Las Bambas por MMG, los frutos de la MDC se extinguieron, sólo quedaron promesas y daños como el primer paquete de endeudamiento.

6.4.2 Mesa de Desarrollo de Challhuahuacho (2015). Surgió luego del paro ocurrido en febrero de 2015. Entre otros, dos hechos contribuyen a su materialización: 1) El PMLB concluyó la etapa de construcción en 2015 lo que disminuyó considerablemente el número de trabajadores; las versiones que circulan al respecto señalan que de 18,000 solo quedarían 3,000;2) El descontento de las comunidades altas del distrito de Challhuahuacho porque el primer dueño no cumplió los acuerdos y además porque resultaban menos favorecidas que las comunidades de la zona de influencia directa. Estos hechos motivaron, a comienzos de febrero de 2015, un paro de 72 horas que en su momento de mayor tensión, ocasionó la retención de un grupo de trabajadores de una empresa subcontratista del PMLB.

Los pobladores tuvieron un pliego de reclamos de 30 puntos. El 28 de febrero se creó la mesa de Desarrollo de Challhuahuacho, promovida por el gobierno nacional, local y las comunidades campesinas y las organizaciones locales. La mesa fue presidida por el Minagri y se conformaron cuatro submesas de trabajo: a) infraestructura social y productiva, b) minería y ambiente, c) desarrollo agropecuario, y d) responsabilidad social. Con la instalación de esta mesa, entre otros objetivos, se buscaba evitar cualquier escalamiento de la violencia y también atenuar la protesta social.

De los 30 puntos de las demandas de lucha fueron seleccionados para ser discutidos los siguientes: 1) oportunidades de empleo, 2) negociación del aporte del $10 \%$ de las utilidades de la empresa, 3) pago por licencia social del agua, 4) servicios de hospedaje y restaurantes, 5) apoyo con movilidad escolar para comunidades, 6) cambio de relacionistas comunitarios, 7) revisión del convenio marco y del anexo $K$, etc. Esta mesa, en esencia, se abocó a beneficiar a las 33 comunidades del distrito de Challhuahuacho.

Según Flores (2016) esta mesa tuvo cinco particularidades: 1) se trató de una mesa de nivel distrital, la de Cotabambas fue provincial, 2) se convocó a partir de un conjunto de demandas (30 puntos) de la sociedad civil y no a partir de pedidos de los gobiernos locales, 3) al considerar también las áreas ambientales de responsabilidad social de la empresa minera, se planteó un abordaje más amplio de lo que se podría catalogar como desarrollo sostenible, 4) se incluyó en el proceso a la empresa minera, 5) la mesa marginó la participación de otros actores sociales y gubernamentales del resto de los distritos de la provincia. Esta exclusión, entre otras, fue una de las grandes limitaciones de esta mesa.

En el PMLB, al igual que en otros similares, las poblaciones más cercanas a la mina buscan tener una negociación directa con la empresa y con el gobierno central, para lograr más beneficios. El resultado de este proceder es la división entre comunidades ubicadas en áreas directa e indirectamente afectadas por la actividad minera.

En marzo de 2015, el ministro de Vivienda, Construcción y Saneamiento lideró un conjunto de reuniones que se denominaron "Taller de Planificación e Intervención de los Sectores Nacionales y Locales para la Provincia de Cotabambas». Al igual que en la MDC no se convocó a los actores de la sociedad civil ni a la empresa a estos talleres. Las consecuencias de estas omisiones se expresan en los conflictos activos y latentes en las Bambas. Estos talleres incrementaron 
la división entre los participantes y los excluidos y el gobierno nacional los usó en el futuro para consumar sus farsas. Luego de los acontecimientos del 28-0915, la Mesa de Challhuahuacho y los talleres antes mencionados resultaron anacrónicos y el gobierno tuvo que implementar una nueva mesa.

6.4.3 La nueva mesa de Cotabambas. Durante el 2015, diversas organizaciones sociales de Cotabambas enviaron cartas al gobierno nacional y a la empresa minera para que expliquen las cinco modificaciones al EIA, tales cartas fueron ignoradas o rechazadas antes y después del conflicto de setiembre de 2015. Como ya se anotó antes, el 28 de octubre, las organizaciones sociales levantaron el paro y al día siguiente hizo lo mismo el gobierno con el estado de emergencia. Varios ministros se comprometieron con los pobladores de Cotabambas y Grau a instalar una nueva mesa de diálogo en la que participarían las organizaciones sociales, alcaldes, empresa minera y el gobierno nacional. Esa mesa debió instalarse el 16 de noviembre; pero el 15 del mismo mes, el gobierno publicó la R.M. No 263-PCM mediante la cual se conformaba «la Mesa de Trabajo para el Desarrollo de la Provincia de Cotabambas». La instalación debió hacerse después de 10 días hábiles de publicada la norma, pero se demoró hasta febrero del año siguiente. Este dispositivo contribuye a incrementar la desconfianza y a incentivar el conflicto, pues en lugar de avanzar se retrocede. Además el gobierno decidió impulsar dos mesas: una para Cotabambas y otra para Grau y como si esto fuera poco se olvidó de los acuerdos de la histórica reunión del 6 de octubre y también quedó en suspenso si esta nueva mesa trataría el tema de las 5 modificatorias al EIA. A pesar de estos hechos negativos «el 29 de febrero de 2016, finalmente, se instala la nueva mesa de diálogo de la provincia de Cotabambas con cuatro ejes de trabajo: (i) Medio Ambiente y Modificatoria del Estudio de Impacto Ambiental (EIA), (ii) Derechos Humanos, (iii) Desarrollo Sostenible, y (iv) Responsabilidad Social Empresarial en las Áreas de Influencia. Sin embargo, las sesiones de los ejes recién comenzaron el 21 de abril de 2016, seis meses después de concluido el paro provincial, «lo que constata la baja prioridad de Cotabambas para las autoridades y ministerios, cuando, en su lugar, deberían hacerse todos los esfuerzos posibles para encontrar puntos de entendimiento con los actores locales» (Flores 2016).
La mesa de diálogo promovida por la PCM, no respondió a las demandas planteadas por los pobladores ni a los compromisos que asumieron varios ministros al concluir el paro indefinido el 28 de octubre. Algunos adjetivos que se han usado para calificar a estas mesas, resultan precisos para este último caso: mecedoras, engañamuchachos.

\section{Conclusiones}

1. El proyecto minero Las Bambas, se ubica en los distritos de Challhuahuacho y Progreso de la provincia de Cotabambas y Grau respectivamente, en el departamento de Apurímac. Se encuentra entre los 3,800 a 4,650 $\mathrm{msnm}$. Inicialmente comprendía territorios ubicados en dos regiones: Apurimac y Cusco. El cambio de dueño obligó a modificaciones sustanciales.

2. Desempeñan un rol protagónico en el conflicto: el gobierno nacional, la empresa minera y las comunidades. En esencia la pugna se da entre dos fuerzas; de un lado, están las organizaciones sociales y sus dirigentes y, del otro, la alianza entre el gobierno y la empresa minera.

3. Hay causas objetivas que originan el conflicto, entre ellas se pueden mencionar:a) La negativa del gobierno a informar a las comunidades sobre las modificaciones en el EIA de Las Bambas. b) El no cumplimiento de las 17 condiciones sociales contenidas en el anexo K. c) Las cinco modificatorias al EIA amparadas en el D.S. No 054-2013-PCM. Este decreto supremo permite a las empresas modificar el EIA sin realizar nuevas audiencias o talleres, tan sólo presentando un Informe Técnico Sustentatorio (ITS) y un Plan de Participación Ciudadana (PPC). d) Debido a las modificaciones del EIA disminuyen las áreas de influencia directa e indirecta. En consecuencia quedan excluidas muchas comunidades y centros poblados de los posibles beneficios del proyecto minero. e) La presentación de actas de talleres supuestamente manipuladas y el desconocimiento de parte de MMG de los compromisos asumidos por Glencore, Xstrata. El cambio de dueño de Las Bambas ha agudizado el conflicto. f) La violencia institucional del Estado expresada en la presencia de la PNP y de militares en la región. g) La contaminación o su amenaza. h) La distribución 
de los beneficios de la minería. i) La difícil compatibilidad entre la actividad minera y agraria. j) La generación limitada de empleos locales, etc.

4. El conflicto está sintetizado en los acontecimientos del 28 de setiembre de 2015. Los hechos anteriores y posteriores a esta fecha explican el desinterés y la indiferencia del gobierno y de la empresa minera por encontrar una solución auténtica a las demandas de las comunidades. El comportamiento del gobierno después de la reunión del 6 de octubre del 2015, lo explica todo.

5. Culpar a los agitadores políticos y a los radicales del estallido del conflicto es el argumento más simple del gobierno, de la empresa minera y de muchos medios de comunicación. El recuento de los acontecimientos ocurridos, antes, durante y después del conflicto prueba que en Las Bambas hay causas coyunturales y estructurales que explican no solamente el conflicto presente, sino también los que ya han ocurrido en el pasado y los que, inevitablemente, se darán en el futuro.

6. Sobre Las Bambas se ha difundido una imagen a nivel nacional e internacional de relaciones armoniosas entre el gobierno, la empresa minera y las comunidades. Esa imagen no se ajusta a la realidad, pues desde la llegada de Xstrata en el 2004 hasta hoy, lo más notorio son las relaciones conflictivas que han sido atenuadas por los proyectos realizados por Proinversión, FOSBAM, gobierno y empresa minera. Todas estas entidades se esforzaron para que el PMLB sea aceptado. Las múltiples y amplias campañas publicitarias contribuyeron a difundir las bondades del proyecto minero, pero apenas él entró en la etapa de producción, se develó la verdadera realidad y el conflicto estalló: las «relaciones armoniosas» no estuvieron sustentadas en bases sólidas.

7. En 2013 se fusionan Xstrata-Glencore. Un año después Las Bambas cambian de dueño. Este hecho agudiza el conflicto, pues se introducen cinco modificaciones al EIA original. Sobre estos cambios solo se informó a las autoridades locales y no a los pobladores de las comunidades. Las protestas trágicas del 28 de setiembre de 2015 y del 14 de octubre de 2016 están directamente relacionadas con los cambios en el EIA que se hicieron sin información transparente a las comunidades. Es un problema que hasta hoy no tiene solución.
8. Xstrata manejó el diálogo, a su favor, con éxito en Tintaya, tenía una amplia experiencia al respecto. Mientras fue dueña de Las Bambas, el diálogo funcionó con relativo éxito, pero cuando el PMLB pasa a la empresa china MMG el diálogo enfrenta nuevas dificultades. La conducción del mismo queda prácticamente en manos del MEM y de la ONDS. Las relaciones asimétricas de poder funcionan en contra de los intereses de las comunidades y sus organizaciones sociales y todo lo que ocurre después de la reunión del 6 de octubre del 2015 expresa nítidamente por qué fracasa el diálogo: el desinterés del gobierno nacional y de la empresa minera.

9. Las mesas de diálogo, trabajo o desarrollo generalmente se han instalado después que el conflicto ha estallado. El gobierno y la empresa minera han decidido cuándo, dónde y cómo se implementan. La última mesa instalada en el 2016, comprueba lo que muchas instituciones e investigadores afirman de ellas: no solucionan los auténticos problemas, son mecedoras, engañamuchachos.

\section{Referencias bibliográficas}

Actualidad Minera del Perú, CooperAcción ( $\mathrm{N}^{\circ}$ s. correspondientes al 2015, 2016 y 2017).

Álvarez, Laura; Godfrid, Julieta y DuÁrez, Jorge (2015). Expansión Minera y Protesta Social en Argentina y Perú, en Investigaciones Sociales Vol. 19, № 35, Lima.

Bebbington, Anthony. (Editor). Minería, movimientos sociales y respuestas campesinas. Una ecología política de transformaciones territoriales. IEP CEPES, Lima, 2007.

Cabrera, Myriam (2014). La comunicación y la administración de conflictos. Implicaciones para el sector extractivo. Lima: PERCAN/MEM. Primera Edición mayo 2004, la siguiente edición ha incorporado nuevos diagramas.

Caretas No 2443, 30-06-16: De Conga a Las Bambas, Lima. Conacami. Willanakuy (Boletín Informativo ańo 3 No 21, diciembre 2003-2004.

CooperAcción (2015). Caso Las Bambas, Informe Especial, Lima.

CooperAcción (2016). Diálogo con fracturas graves: Las Bambas (Informe Especial), Lima.

Cuadros, Julia (2010). Impactos de la minería en la vida de hombres y mujeres en el sur andino. Una mirada desde 
el género y la interculturalidad. Los casos Las Bambas y Tintaya. Lima: CooperAcción.

Cuadros, Julia, Consiglieri Jaime, De Echave José (2005). Mapeo de la situación social e institucional del proyecto Las Bambas. Lima: CooperAcción.

De Althaus, Jaime (2015). ¿Qué falló en las Bambas? El Comercio 02-10-15.

De Echave, José; Hoetmer, Raphael; Palacios, Mario (coordinadores) (2009). Minería y territorio en el Perú. Conflictos, resistencias y propuestas en tiempos de globalización. Lima: Programa Democracia y Transformación Global, CONACAMI, Cooperacción, UNMSM

De Echave, José y otros (2009). Minería y conflicto social. Lima: IEP, CIPCA, CBC, ICES.

De Echave, José (2012). Apurimac, la gestión del territorio y minería. Cusco: GRET, cbc, CooperAcción.

Defensoría del Pueblo (2007). Los conflictos socioambientales por actividades extractivas en el Perú. Lima,

Defensoria del Pueblo (2012). Violencia en los conflictos sociales. Lima.

Defensoria del Pueblo (2015). Reporte Mensual de Conflictos Sociales No 139 y 140 , setiembre y octubre.

Díaz Cartagena, Walter (2016). Gestión estratégica de relaciones comunitarias en el sector minero. Lima noviembre.

Durand, Francisco (2009). Tintaya y su Gobierno minero. Quehacer No 173, Lima.

Durand Lazo, Julio (2010). A propósito del reasentamiento de la comunidad de Fuerabamba.

El Comercio (Editorial). La Ley y el desorden, 04-10-15.

El Comercio (Editorial). Entre proyectos y protestas 06-11-16.

FernándeZ, Rafael (2005). Incidencia de las actividades mineras en la calidad de las aguas subterráneas. CEPISOMS, junio.

Flores, César (2016). Conviviendo con la minería en el sur andino. Lima: CooperAcción, Oxfam.

Flores, César; Carlos Quiñones, Epifanio Baca y José De Echave (2017). Recaudación fiscal y beneficios tributarios en el sector minero a la luz de los casos Las Bambas y Cerro Verde. Lima: CooperAcción, Grupo Propuesta Ciudadana y OXFAN.

Guerra, Sandra (2016). Todos hablan de Las Bambas, Velaverde, mayo 10-2016.

Gouley, Clotilde (2005). Conflictos mineros, interculturalidad y políticas públicas: el caso de Las Bambas, provincias de Cotabambas y Grau, departamento de Apurimac.
Centro Bartolomé de Las Casas. Lima: Consorcio de Investigación Económica y Social.

Hoetmer, Raphael (2013). Minería, movimientos sociales y las disputas del futuro: claves de lectura y pistas de reflexión-acción. En Hoetmer, R. y otros (editores).

Hoetmer, Raphael, Miguel Castro, Mar Daza, José De Echave y Clara Ruiz (editores) (2013). Minería movimientos sociales en el Perú. Instrumentos y propuestas para la defensa de la vida, el agua y los territorios. Lima: PDTG, CooperAcción, ACSUR, Entre Pueblos.

Huamaní, Giselle (2011). La herencia de los conflictos. Ideele No 210.

Huamaní, Giselle y otros (2012). Hacia una mejor gestión de los conflictos socioambientales en el Perú. Lima: Consorcio de Investigación Económica y Social (CIES).

Huillcahuanaco, Nancy (2012). Nuevas dinámicas socioespaciales en el ámbito del Proyecto Minero "Las Bambas" en la región Apurímac, analizadas en la perspectiva del desarrollo local-regional. Tesis para optar el título profesional de Geógrafa, UNMSM, Lima.

La República (Editorial). Las Bambas ahora 02-10-15.

León, Camilo (2015). Reubicación de poblaciones por proyectos mineros en el Perú. Diferencias por género y edad. En Enriquez, N; Gerardo Damonte, Manianne Braig y Bárbara Gobel (editores, 2015). Desigualdades en un mundo globalizado. Lima: CISEPA, PUCP.

Luque, Rolando (2016). Entrevista en El Comercio de Francesca García, 03-10-16.

MMG Limited (2016). Las Bambas Perú.

Montoya, Rodrigo (2015). Muerte en Las Bambas, carnaval del BM y el FMI en Lima, Diario UNO, 11-10-15.

Navarro, Moisés (2015). Tras bambalinas. En Poder Enterprise, noviembre.

Observatorio de Conflictos Mineros en el Perú (2015, 2016 y 2017). Cooperacción, Fedepaz, Grufides. Reportes, Lima.

Oxfam-América (2003). Invirtiendo en la destrucción: los impactos de un acuerdo de inversión de la OMC sobre las industrias extractivas en los paises en desarrollo. Lima.

Oxfam GB (2008). Pobreza, desigualdad y desarrollo en el Perú, informe anual 2007-2008. Lima.

Proinversión (2005). Las Bambas: un modelo de desarrollo sostenible. Lima.

Requena, José (2015). Las Bambas: La tentación de la simpleza. El Comercio 04-10-15.

Ríos Quinteros, Lucio (2010). Percepciones y retos sociales de la minería. Lima, IIMP, Jueves Minero, 18-02-2010.

Robles Mendoza, Román (2015). Lucha por el agua en las explotaciones mineras. Lima. 
Saldarriaga, Juan (2015). El futuro de Las Bambas en medio del conflicto. El Comercio, Día 1, 05-10-15.

SaldarRiaga, Juan (2015). Matarani: megapuerto minero. El Comercio, Día 1, 28-09-15

Scurrah, Martín (ed.) (2008). Defendiendo derechos y promoviendo cambios. El Estado, las empresas extractivas $y$ las comunidades locales en el Perú. Lima: Oxfam Internacional, Instituto del Bien Común, Instituto de Estudios Peruanos.

Semana Económica. Las Bambas: ¿Game Over? Año XXXI, $\mathrm{N}^{\circ} 1489,04-10-2015$

Sociedad Nacional de Minería, Petróleo y Energía (2016).

El impacto de Las Bambas en la Región Apurímac, Lima, Octubre.
TORRES, Javier (2015). La minería no puede ser una historieta. En Poder Enterprise, setiembre.

Velardi, Nicoletta y Zeisser, Marco (editores, 2012). Anales Seminario Internacional. Desarrollo Territorial y Extractivismo. Luchas y Alternativas en la región Andina. GRET, cbc, CooperAcción, Cusco.

VIvas, Fernando (2015). ¡Pero si Las Bambas era perfecto! $L a$ República 30-09-15

Xstrata Cooper. Desarrollo sostenible en Las Bambas: inversión social 2005-2011.

Zapata, Antonio (2015). Las crisis en Las Bambas, La República 07-10-15. 


\section{ANEXO K}

\section{Anexo $\mathrm{K}$ de las Bases del concurso público internacional para el proyecto Las Bambas}

Fuente: Prolnversión (2004), "Anexo K. Condiciones sociales para la explotación del proyecto minero Las Bambas", Bases del concurso público intemacional $N^{*}$ PRI-80-2003. Promoción de la inversión privada en el proyecto Las Bambas - Departamento de Apurimac.

\section{"Anexo k. Condiciones sociales para la explotación del proyecto minero Las Bambas".}

El presente Anexo recoge las propuestas obtenidas como resultado de las audiencias públicas, coordinaciones y diálogo sostenido por PROINVERSIÓN con las autoridades regionales. locales y comunales del Departamento de Apurimac, según se exponen a continuación:

1. Ejecución de un Estudio de Impacto Ambiental de conservación del medio ambiente, la flora, la fauna y los recursos hidricos.

2. Brindar oportunidad de trabajo para los profesionales. técnicos y obreros de la provincia y región del Departamento de Apurímac como prioridad.

3. Ejecución de inversión en proyectos de infraestructura básica sociales.

4. La reubicación de las comunidades afectadas se efectuará en condiciones adecuadas. previo pago de justiprecio conforme a ley.

5. Se efectuará la reposición de tierras y pasturas afectadas.

6. Implementación de programas de sanidad animal y agraria.

7. Transferencia de tecnologia y asistencia técnica en programas de cultivo y crianza.

8. Apoyo en la comercialización de productos agricolas y pecuarios.

9. Respeto a la cultura, costumbres y fundamentalmente a los derechos humanos.

10. Seguro de salud para los comuneros afectados.

11. Asignación preferencial de las regalias y del canon minero para las comunidades afectadas, distrito, provincia y la región.

12. Fiscalización externa con participación de especialistas para evaluar cuantitativa y cualitativamente el grado de contaminación de los recursos hídricos. suelo y otros. en forma periódica, acompañado por un comité de medio ambiente orientado a la prevención de los impactos negativos.

13. Responsabilidad social y ambiental de las empresas, estableciendo relaciones positivas con las comunidades.

14. Integrar y armonizar el desarrollo minero con actividades agropecuarias.

15. Los proyectos de contratos serán de conocimiento de los habitantes de la provincia y la región.

16. La suscripción del contrato se realizará en el lugar del proyecto. con pleno conocimiento de las autoridades y la sociedad civil.

17. Los recursos generados por el proyecto se canalizaran a las comunidades involucradas de la provincia y región esperando que el proyecto minero sea responsable y que genere un desarrollo sostenible.

Es responsabilidad del Optante y del Adquirente. según corresponda, lo establecido en los Numerales 1, 2, 4, 5 , 9. 13 y 14 dentro de los alcances y estipulaciones contenidas en los Contratos de Opción y de Transferencia, cuya supervisión corresponde a PROINVERSION. El cumplimiento de las otras condiciones es de responsabilidad del Ministerio de Energia y Minas, Ministerio de Economia y Finanzas, y PROINVERSIÓN, de acuerdo a lo establecido en los Contratos antes citados. la regulación del Fideicomiso, la normatividad ambiental y la legislación vigente. 